\title{
AN ERGONOMIC APPROACH TO DESIGN HAND BLOCK TOOL FOR TEXTILE PRINTING HANDICRAFT INDUSTRY
}

\author{
M. L. Meena, G. S. Dangaych and A. Bhardwaj \\ Department of Mechanical Engineering, Malaviya National Institute of Technology \\ Jaipur, India
}

\begin{abstract}
Hand block textile printing is an important operation in small scale textile industries of India. Hand tool mechanisms designed to reduce the various risk factors have rarely been studied. To make comfortable handle design, musculoskeletal disorders prevalence investigation of workers associated with hand block printing operation has been done. Data related to musculoskeletal discomfort were collected from 80 workers (age group 18-60 years) using questionnaire. Rapid upper limb assessment (RULA) technique was applied for postural analysis. New hand block tool was designed using Autodesk Inventor 2014 (Educational Institute Version i.e. V5R12) and then analyzed with HyperMesh (Version 12.0) software. Most of the workers reported that working with existing hand block tool is not comfortable. RULA technique resulted as final score of arm and wrist for the working with existing hand block tool was found out to be 5. After the modifications in hand block tool by using the ergonomics principles and anthropometric data, RULA final score of arm and wrists for the working with developed hand block tool was found out to be 3. The developed hand block tool has been revealed to be better than the existing one in term of comfort level, it is improved $42.69 \%$ and production rate $29.62 \%$ increase as compared to the existing hand block tool, it could offer an improved working facility and trim down unwanted workplace injuries.
\end{abstract}

\section{KEYWORDS}

Ergonomics, Hand Tool, Injuries, Musculoskeletal Disorders, Workplace.

\section{INTRODUCTION}

India has a rich heritage of manual work in handicrafts like: hand block printed textiles, blue pottery, jems, jewellery, sculpture, textile screen printing, and wood handicraft etc. Handicraft operation which can be distinct simply as items produced by skill of hand which represent a part of the worker's temperament in addition to as centuries of evolutionary tradition [1]. More than $90 \%$ of workforce and about $50 \%$ of the national product are accounted for the informal economy [2].

The hand block tool also known as a block is most commonly used hand block tool for textile printing. The hand block tool is used in awkward position. The hand block tool consists of a rectangle wooden block with fixed to a handle which is an integral part of rectangle block. Various shapes and sizes are available for different hand tools depending on work (see Figure 1). For operation, the handle of the block is held in the hand, head raised and punched into the work table (i.e. fabric/cloth/bed sheet) for printing. Use of hand block tools in printing may require exertion of significant hand force while shoulder, hand and wrist may be in awkward postures (see Figure 2).

DOI : 10.14810/ijmech.2015.4402 
International Journal of Recent advances in Mechanical Engineering (IJMECH) Vol.4, No.4, November 2015

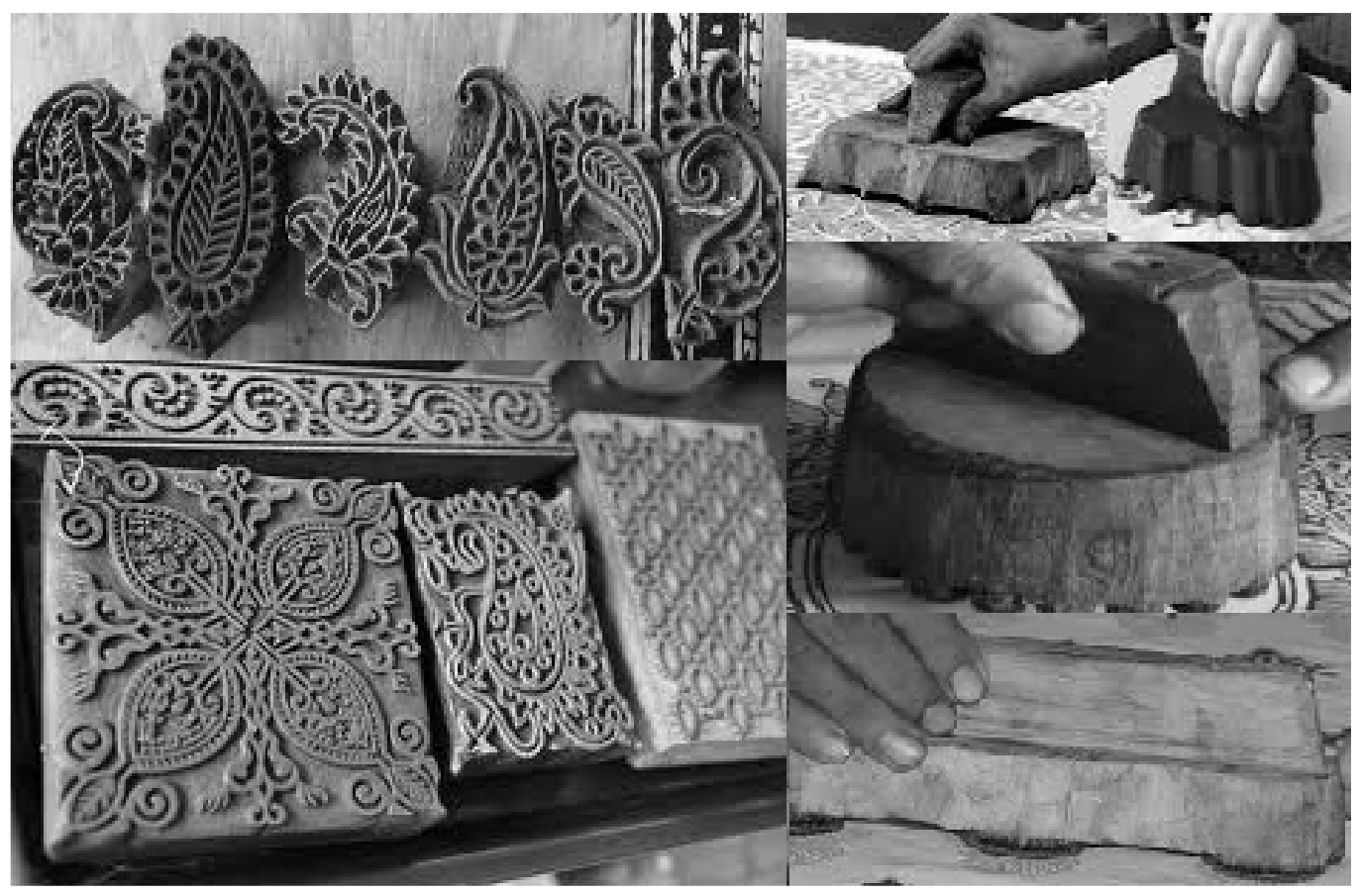

Figure 1. Different shapes and sizes of hand block tool

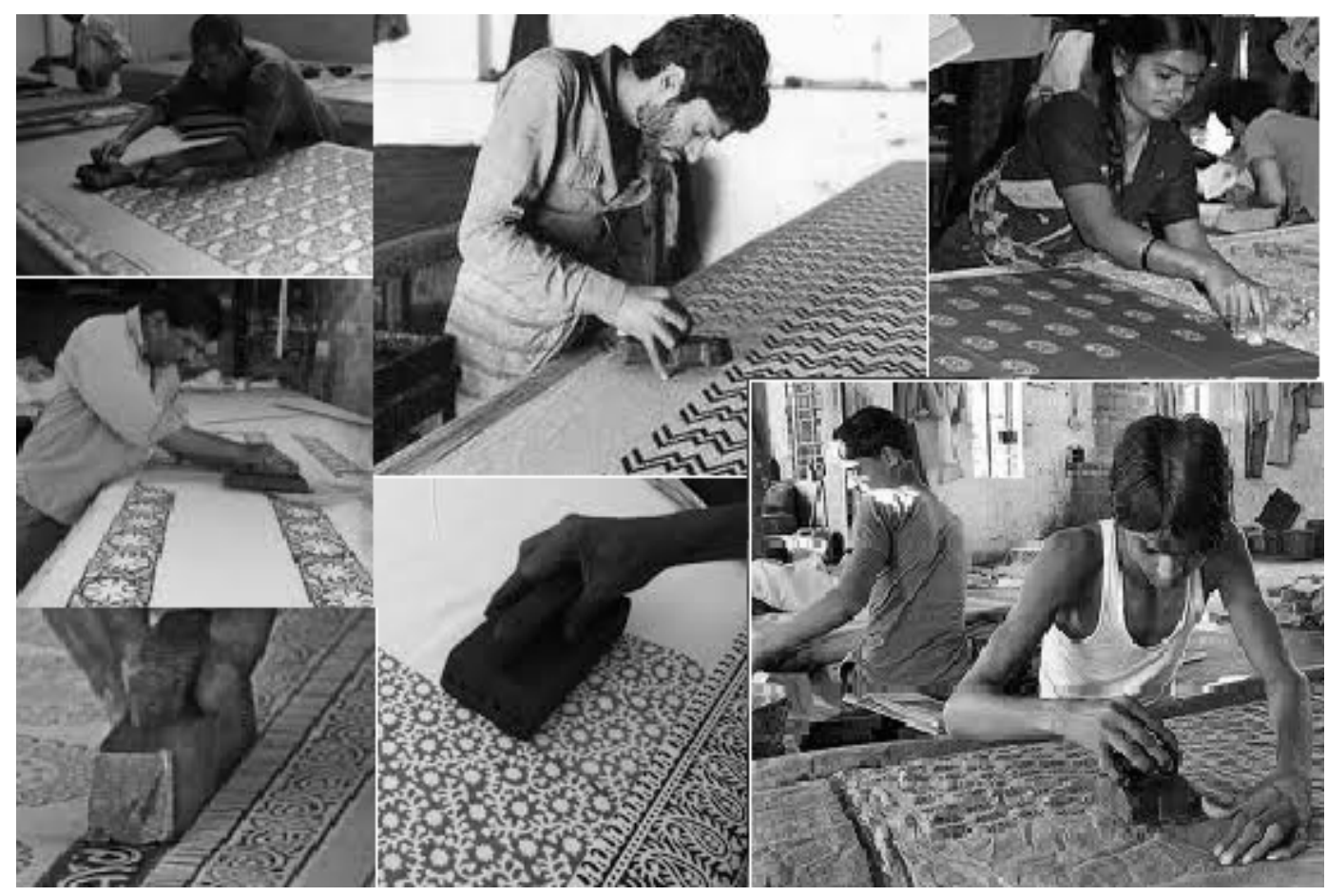

Figure 2. Textile printing operations with hand block tool 
Risk factors for hand/wrist problems have been developed due to unnatural postures and repetitive forceful exertion. By using proper anthropometric data, ergonomic interventions and technological advancement, musculoskeletal disorders can be reduced, fatigue and productivity increased [3]. These tools further can also be used to increase turnover rates and employee engagement [4-15]. The present study was undertaken with the following objectives:

1. To investigating the prevalence of musculoskeletal disorders in workers;

2. To analysis of worker's posture by using RULA technique;

3. To modified the hand block tool.

\section{RESEARCH METHODOLOGY}

Following steps were followed to carry out this research.

- Testing and evaluation the existing hand block tool in the field

- Measuring the musculoskeletal disorders (MSDs) using modified questionnaire of Standard Nordic Questionnaire[16]

- Measuring overall discomfort rate using Comfort Questionnaire for Hand tools $(\mathrm{CQH})$ which is an adoption of [17]

- Postural analysis using Rapid Upper Limb Assessment (RULA) method [18]

- Modeling of existing hand block tool in Autodesk Inventor

- Modifying the existing hand block tool ergonomically according to HyperMesh and anthropometric data

- Testing the modified hand block tool again in the field.

- Measuring again, the MSDs among workers again with modified hand block tool

- Evaluation of overall comfort or discomfort of workers with modified tool using $\mathrm{CQH}$

- Postural analysis using RULA method again.

- Comparisons between existing and modified hand block tool

\section{DATA OBSERVATION AND ACTIVITY ANALYSIS}

In the hand block textile printing industries, activities were mostly carried out for long periods in a standing position from 30 minutes to 2 hours and extended from 8 to 10 hours depending upon requirements. The work was mainly light with high static muscular loads on the forearm. Since these type of work were light, grip had to be a "pinch" type, which further increased the static load on the muscles of wrists and hand.

A modified questionnaire of standard Nordic questionnaire [16] was used to collect the data and analysis of activities. Some questions were developed based on the method as described by Sinclair [19]. Three versions of the questionnaires were made, validated, refined and then a final questionnaire was prepared. The questionnaire comprised questions pertaining to different problems related to textile hand block printing such as: daily activity; resting periods; discomfort; and working hours. Photography and videotaping techniques were used to record the textile block printing process as well as the tools used. The photographs were later analyzed for problems like twisting and bending wrists/hands in the laboratory. 


\section{MODELING AND ANALYSIS OF HAND BLOCK TOOL}

Modeling and analysis of a hand block tool can be divided into two phases. First modeling of tool in Autodesk Inventor software and secondly analysis of tool using HyperMesh software. Before modeling and analysis of new hand block tool, measurements of anthropometric data and calculations of dimensions using ergonomic hand tool design principles are required.

\subsection{Measuring Hand Anthropometric Data}

The population comprises of age group 18-60 yrs, mean age of 37.4 years with standard deviation of 10.7. However, Table 1 presents $5^{\text {th }}, 50^{\text {th }}$ and $95^{\text {th }}$ percentiles of anthropometric measurements of participants.

Table 1. Percentile values of hand anthropometric measurements of workers

\begin{tabular}{|c|l|c|c|c|}
\hline \multirow{2}{*}{$\begin{array}{c}\text { S. } \\
\text { no. }\end{array}$} & \multirow{2}{*}{$\begin{array}{c}\text { Anthropometric } \\
\text { measures }\end{array}$} & \multicolumn{3}{|c|}{ Percentile (in millimetre) } \\
\cline { 2 - 5 } & Stature & 1646.1 & $\mathbf{5 0}^{\text {th }}$ & $\mathbf{9 5}^{\text {th }}$ \\
\hline 1 & Hand length & 172.5 & 174.6 & 1795.7 \\
\hline 3 & $\begin{array}{l}\text { Hand breadth at } \\
\text { metacarpals III }\end{array}$ & 79.4 & 90.9 & 199.6 \\
\hline 4 & Maximum grip length & 122.5 & 140.2 & 97.8 \\
\hline 5 & Palm length & 103.5 & 122.2 & 149.7 \\
\hline 6 & Grip diameter, inside & 33.6 & 36.9 & 37.7 \\
\hline 7 & Grip diameter, outside & 47.8 & 53.8 & 58.4 \\
\hline
\end{tabular}

\subsection{Ergonomic Principles Considerations in the Design of Hand Tools}

Poorly designed hand block tools may be too heavy, poorly balanced, with sharp edges and corners, have a large grip of wrong shape, or slippery. Deviations of the wrist from the neutral position under repetitive load can lead to a variety of cumulative trauma-disorders as well as decreased performance. Ergonomic hand-tool design principles were used to design a new hand block tool. To design the shape and handle length of hand block, the hand anthropometric database and printing practice were the basic considerations. Physical factors taken into consideration for developing new handle of hand block tool using ergonomic principles adopted in previous studies [20,21,22].

\subsection{Design and Analysis of Hand Block Tool Design}

Based on the above listed ergonomics principles, it is obvious that the existing hand block tool may not be ergonomically designed in shape and/or in dimensions. Anthropometric data were calculated to new hand block tool for the block printing workers. According to Lewis and Narayan [20], the length of handle was calculated using hand breadth at metacarpals III (see Table 1) [[(P50th hand breadth of males+P95th of hand breadth of males)]/2] +15: [[(90.9+ $97.8) / 2$ ] $=94.35+15=109.35 \mathrm{~mm}$ ]. Narayan [20] also suggested that the length of handle should be increased by 15 millimeters for preventing contact stress on the palm of hand. Kong and Lowe [23] suggested that to provide highest power grip strength, range of handle diameter for male was $38.6 \mathrm{~mm}$ to $40.3 \mathrm{~mm}$ if range of hand length was $196.3 \mathrm{~mm}$ to $205.0 \mathrm{~mm}$. On the basis of anthropometry data, the designed hand block tool to have its diameter at $38.9 \mathrm{~mm}$ for hand length was $199.6 \mathrm{~mm}$. 
Hand block tool was modelled and designed using Autodesk Inventor 2014. Figure 3 shows the isometric views of designed hand block tool. After modeling part, the design was saved in IGES format to import in HyperMesh. Analysis of hand block tool with HyperMesh. Figure 4 shows the isometric views of meshed block tool.
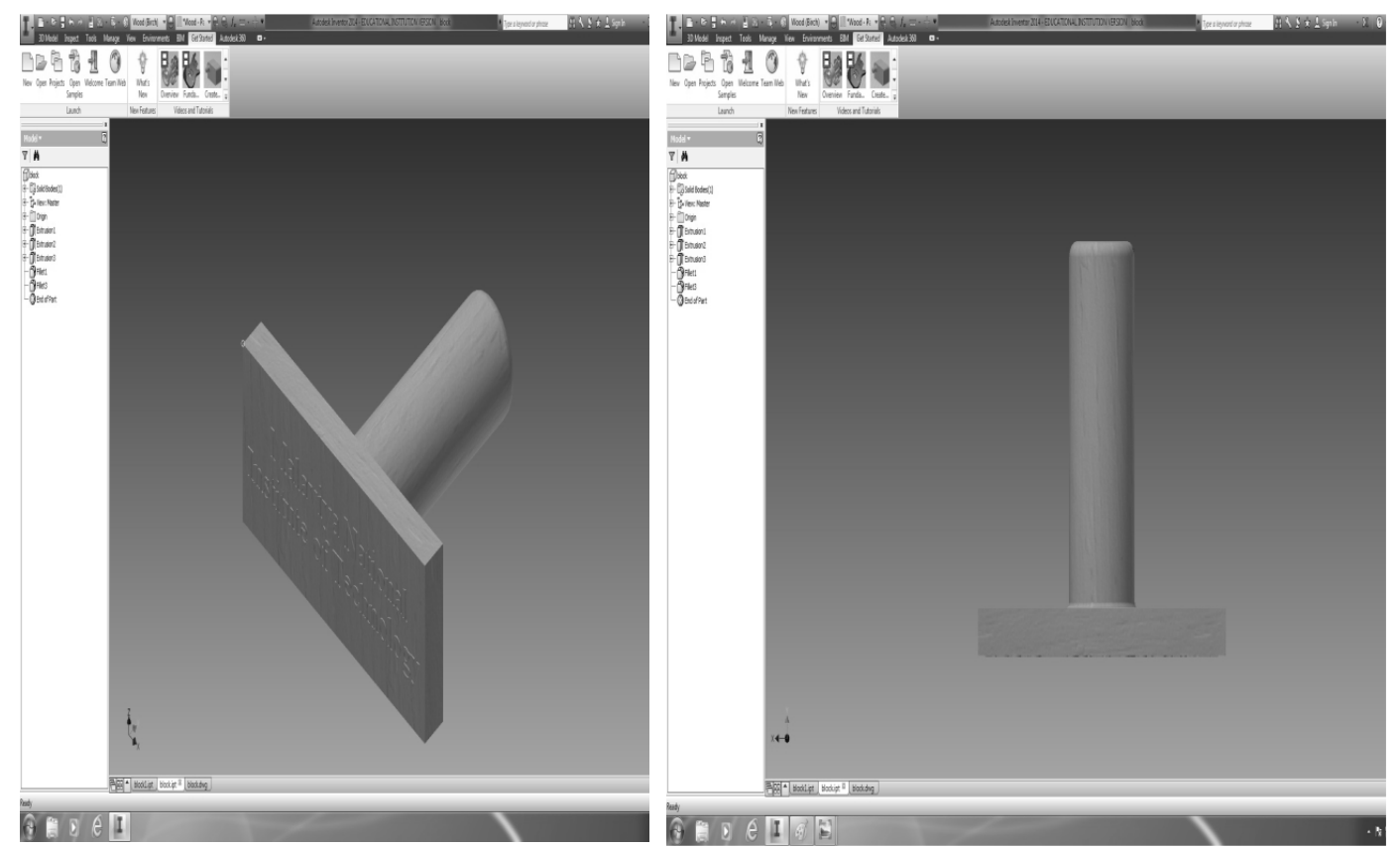

Figure 3. Isometric view of hand block tool in Autodesk Inventor 2014
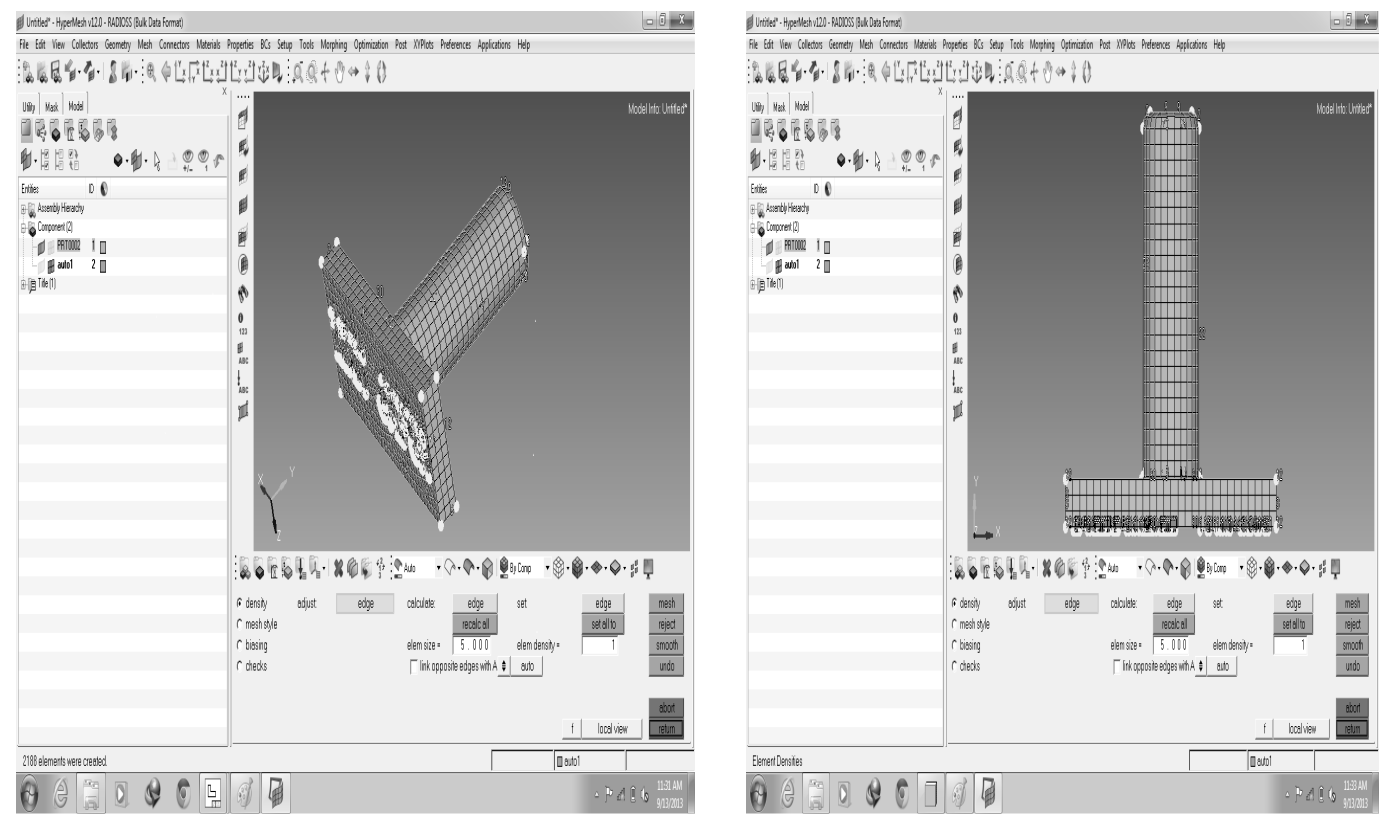

Figure 4. Isometric view of meshed hand block tool in HyperMesh 


\subsection{Modifications in Hand Block Tool}

The hand block tool modeled with the help of HyperMesh software for finding an optimal design, which revealed that there are still some working possibilities for developing hand tool. The worker's wrist is bent from neutral position during working with existing hand block tool and the main problem was unnecessary compression in the middle of the palm due to short handle length. The handle of the existing hand block tool is shorter in length and thickness, being about 30-50 $\mathrm{mm}$ and 5-10 $\mathrm{mm}$ respectively. Length, width and thickness of hand tool depend on the size of block (see Figure 5), which is cumbersome for the worker due to bending in their wrists. The current research team has provided handle length of $109.35 \mathrm{~mm}$ and handle diameter of $38.9 \mathrm{~mm}$, using the anthropometric data for worker. The handle size and shape of developed hand block tool shown in Figure 6.

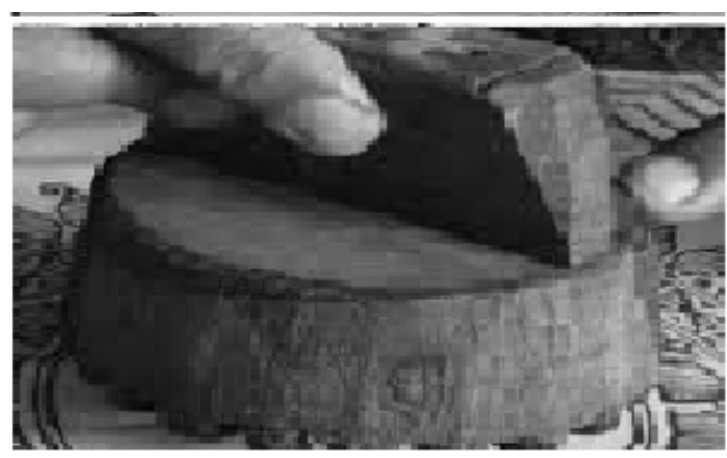

Figure 5. Handle sizes of existing hand block tools

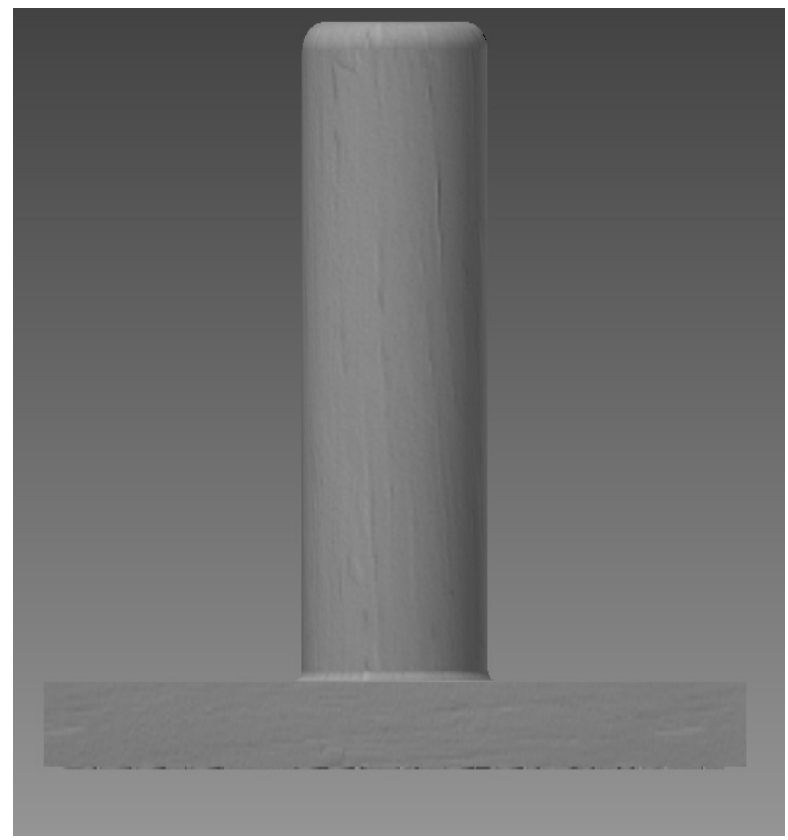

Figure 6. Handle sizes of developed hand block tools

Rounded handles minimize compression on the palm. In addition, handle diameter has been increased to provide a better gripping facility using anthropometric data. 


\section{RESULTS AND DISCUSSION}

To reduce musculoskeletal disorders, improved hand block tool has been designed. From the ergonomic point of view it is observed from present study that working with existing available hand tool is not comfortable. To provide comfort, rounded handle of hand block tool in rounded in particular profile is recommended. The handle of existing tool is flat and causing wrists strain due to bending/twisting of wrists. It also reduces the workers comfort during long hour operations, therefore causing more fatigue.

\subsection{Comparison of MSDs for Existing and Developed Hand Tool}

Comparisons of the musculoskeletal disorders in body region for existing and modified hand block tool are presented in Table 2. The prevalence of musculoskeletal disorders among workers for existing and developed tool was evaluated using modified musculoskeletal disorder questionnaire. Table 2 and Figure 7 show that there is significant reduction in MSDs pain with new hand block tool.

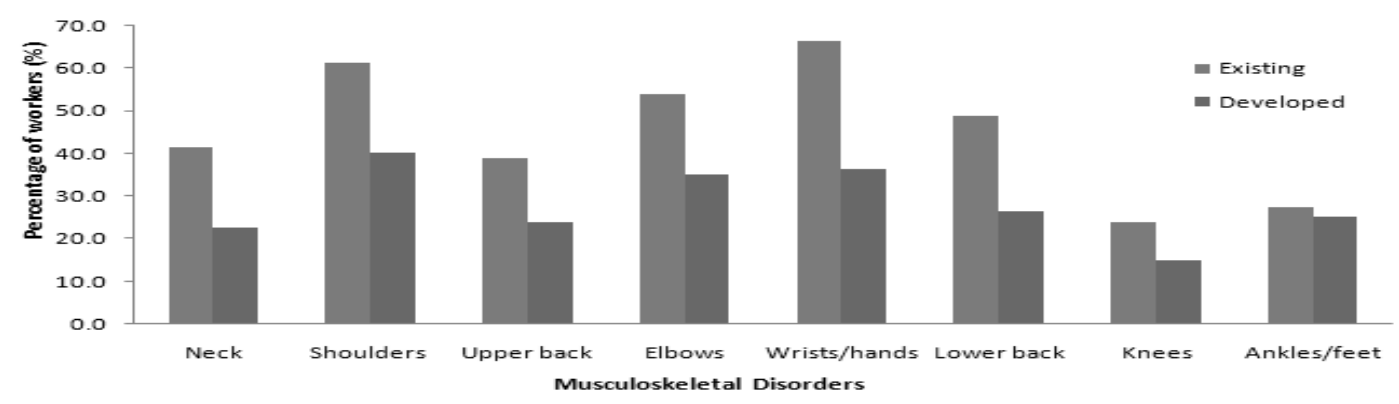

Figure 7. Comparision of prevelence of MSDs for existing and developed tool

Table 2. Prevalence of MSDs among workers for existing and developed tool

\begin{tabular}{|c|c|c|c|c|c|}
\hline \multirow{2}{*}{$\begin{array}{l}\text { MSDs affected } \\
\text { body regions }\end{array}$} & \multicolumn{2}{|c|}{ Existing tool } & \multicolumn{2}{|c|}{ Developed tool } & \multirow{2}{*}{$\begin{array}{c}\text { Reduction in } \\
\text { MSDs } \\
(\%)\end{array}$} \\
\hline & $\begin{array}{c}\begin{array}{c}\text { Number } \\
\text { of } \\
\text { workers }\end{array} \\
\end{array}$ & $\begin{array}{c}\text { Percentage } \\
\text { of workers } \\
(\%)\end{array}$ & $\begin{array}{c}\text { Number of } \\
\text { workers }\end{array}$ & $\begin{array}{c}\text { Percentage } \\
\text { of workers } \\
(\%)\end{array}$ & \\
\hline Neck & 33 & 41.3 & 18 & 22.5 & 45.5 \\
\hline Shoulders & 49 & 61.3 & 32 & 40.0 & 34.7 \\
\hline Upper back & 31 & 38.8 & 19 & 23.8 & 38.7 \\
\hline Elbows & 43 & 53.8 & 28 & 35.0 & 34.9 \\
\hline Wrists/hands & 53 & 66.3 & 29 & 36.3 & 45.3 \\
\hline Lower back & 39 & 48.8 & 21 & 26.3 & 46.2 \\
\hline Knees & 19 & 23.8 & 12 & 15.0 & 36.8 \\
\hline Ankles/feet & 22 & 27.5 & 16 & 20.0 & 27.3 \\
\hline
\end{tabular}




\subsection{Comparison of CQH of an Existing and Developed Tool}

Overall discomfort rating was measured using Comfort Questionnaire for Hand tools (CQH), which is an adopted from Corlett and Bishop (1976). Table 3 shows the sum and mean score for perception of workers about existing and developed hand block tool.

Table 3. Analysis of existing and developed hand block tool

\begin{tabular}{|c|c|c|c|}
\hline & Existing tool & Developed tool & $\begin{array}{c}\text { Improvement } \\
(\%)\end{array}$ \\
\hline $\begin{array}{c}\text { Sum of } \\
\text { perception }\end{array}$ & 267 & 381 & $42.69 \%$ \\
\hline $\begin{array}{c}\text { Mean of } \\
\text { perception }\end{array}$ & 3.34 & 4.76 & $42.69 \%$ \\
\hline
\end{tabular}

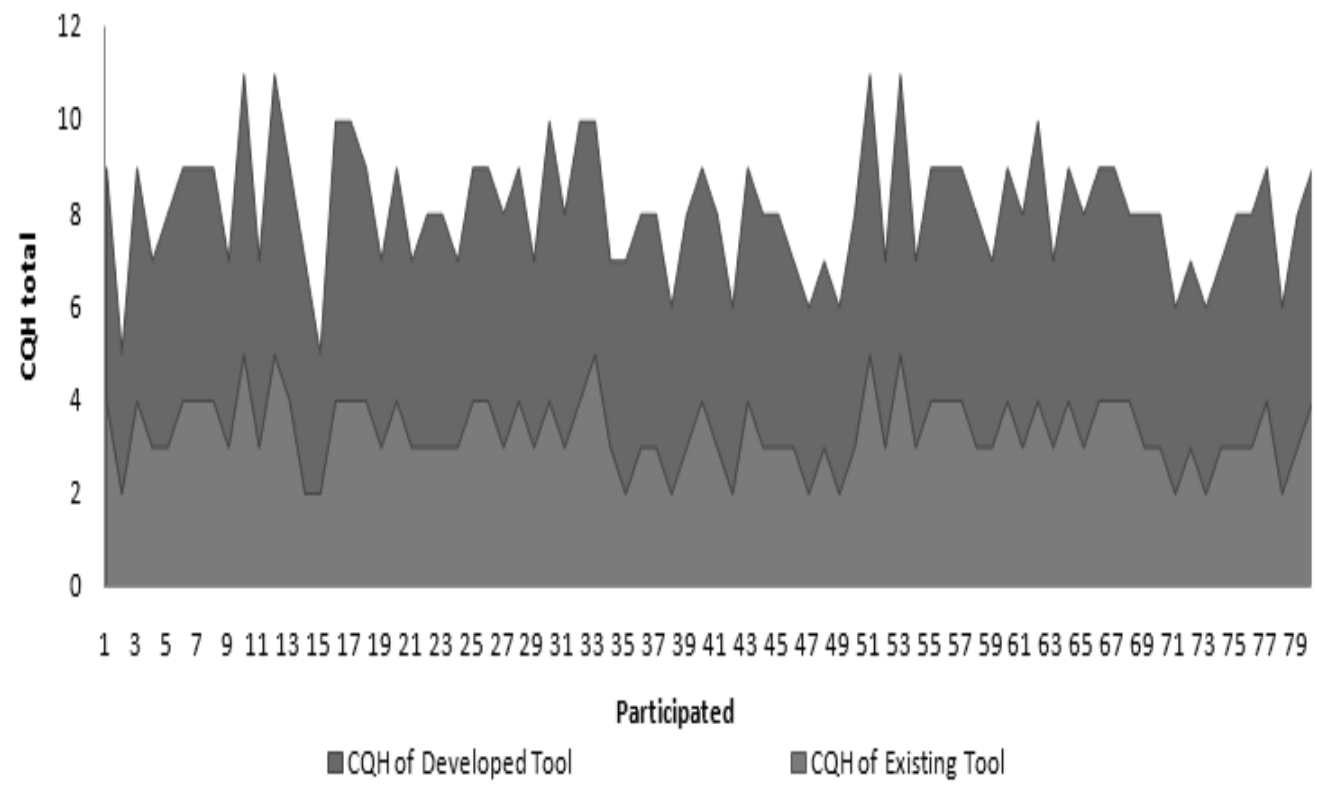

Figure 8. Comparison of $\mathrm{CQH}$ for exisitng and developed tool

From the Table 3, 42.69\% improvement in comfort level was observed with developed hand block tool. Figure 8 shows the comparison of $\mathrm{CQH}$ for exisiting and developed hand tool. It indicates that working with modified hand block tool is better than the working in the conventional hand block tool.

\subsection{Comparisons of RULA Score for Existing and Developed Tool}

RULA technique resulted as final score of arm and wrists for the existing conditions were found out to be 5. After the modification in hand block tool by using the ergonomics principles and anthropometric data, final grand score for the developed hand block tool was found out to be 3 . Developed hand block tool are validated by using RULA technique. 


\subsection{Judgment of Workers about Existing and Developed Tool}

In all, $81 \%$ of the workers perceived the postures in the new working hand block tool better/comfort during work. Figure 9 shows that the general judgment of the workers about the modified hand block tool in comparison to the conventional hand block tool. Most of the workers are satisfied with modified hand block tool which have been proved by CHQ result analysis.

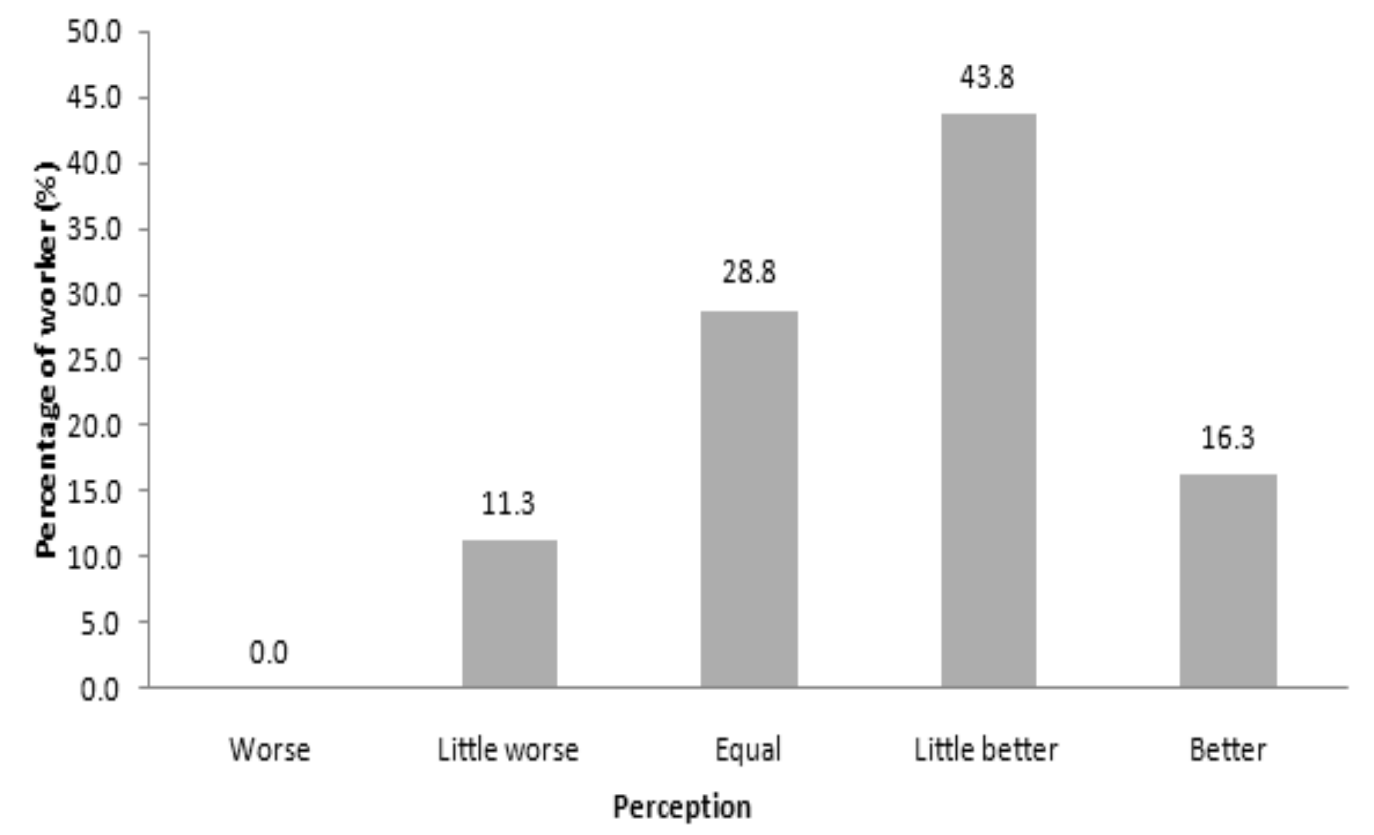

Figure 9. General judgment of the workers about working with modified hand block tool in comparison to the conventional hand block tool $(\mathrm{n}=80)$

In improved hand block tool, handle bar is rounded to ensure that wrist remains straight while working. It increases worker's comfort while working. As such modified tool which is having less weight is a better, it is seen that MSDs are reduced with lighter tool. Figure 10 shows the duration of continuous work with existing and modified working conditions. With modified hand block tool, it is observed that an average worker can work 57 minutes without resting in spite of 41 minutes with conventional conditions. Figure 11 shows that production rate with existing and modified working condition and hand tool. If per day work is calculated than it is found that a skilled workers can print 35 meters of fabric in a day with modified working condition compared to 27 meters with traditional hand block tool. 


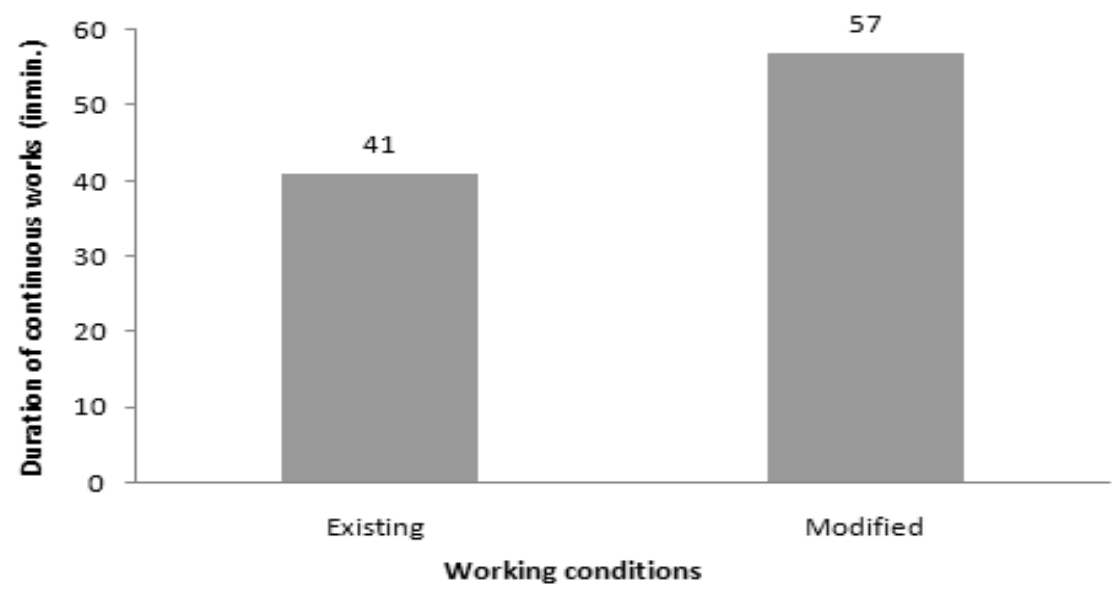

Figure 10. Duration of continuous works with exisiting and modified working conditions

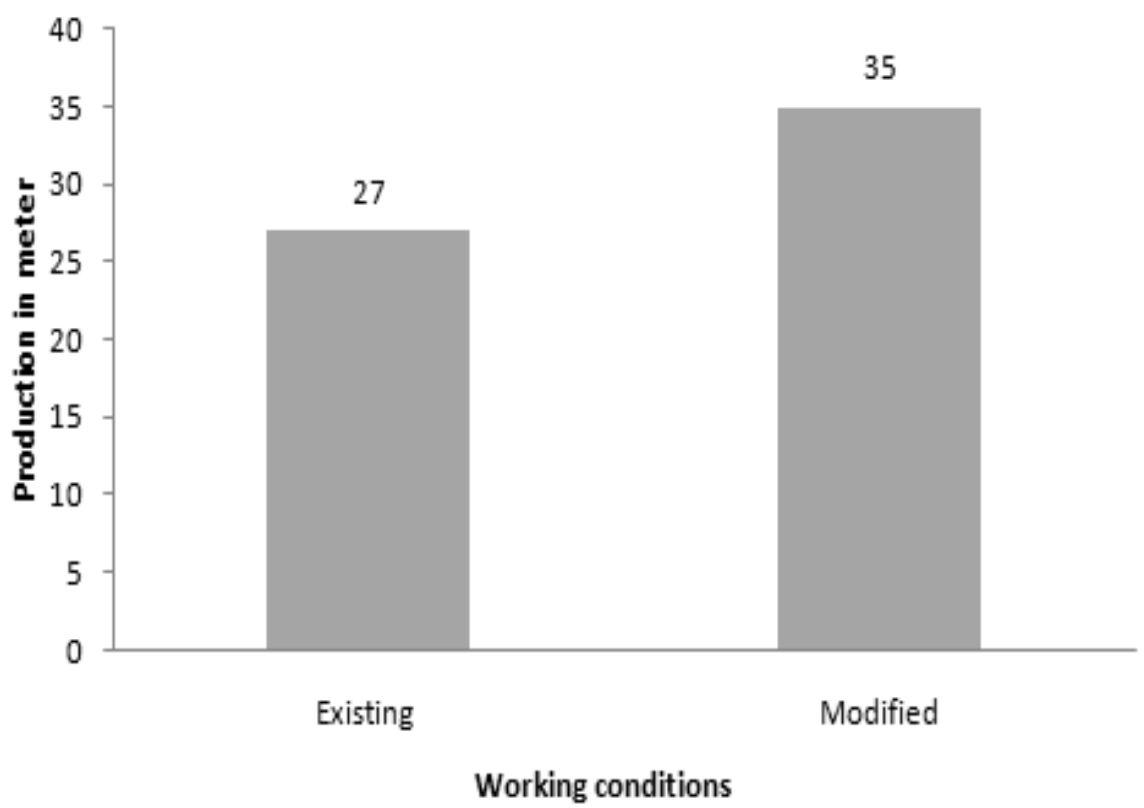

Figure 11. Hand block printing production in a day with existing and modified hand tool

This research indicates a way forward to improve the hand block tool design and construction. Finally, it should be acknowledged that ergonomics does not change process immediately; rather it is a gradual process which must consider many factors. In this present research, handle design may not be ultimate solution but may be a step closer to satisfactory design.

\section{CONCLUSION}

In the present study, hand block tool for textile printing was redesigned and compared to the existing hand block tool. The modified hand block tools have better efficiency with less wrists/hands fatigue as compared to existing hand tool. The developed hand block tool has been shown to be better than the existing one in term of comfort level (improvement $42.69 \%$ ) and production rate (improvement $29.62 \%$ ) as compared to the existing hand tool, it could offer an improved working facility and trim down unwanted workplace injuries. 


\section{ACKNOWLEDGEMENTS}

The authors are grateful to the all workers of hand block textile printing industries, who served as volunteers for the measurements and also for questionnaire studies.

\section{REFERENCES}

[1] M. L. Meena, G.S. Dangayach, and A. Bhardwaj, "Occupational risk factor of workers in the handicraft industry: a short review", International Journal of Research in Engineering and Technology, Vol. 1, No.3, pp. 194-196, 2012

[2] National Statistical Commission (2012) Report of the committee on unorganized sector statistics [online]. http://mospi.nic.in/mospinew/. (Accessed 14 June 2015).

[3] R. Jain, S. Gupta, M. L. Meena, and G.S. Dangayach, "Optimization of Labour Productivity using Work Measurement Techniques”, International Journal of Productivity and Quality Management [in press].

[4] A. Choobineh, M. Hosseini, M. Lahmi, R. Khani, and H. Shahnavaz, "Musculoskeletal problems in Iranian hand-woven carpet industry: guidelines for workstation design", Applied Ergonomics, Vol. 38, No. 5, pp. 617-624, 2007.

[5] M.S. Khidiya,and A. Bhardwaj, "Design, development and ergonomics evaluation of hand operated spade", Ergonomics Australia, Vol. 24, No. 1, pp. 15-30, 2010.

[6] P. Mukhopadhyay, and S. Srivastava, "Ergonomics risk factors in some craft sectors of Jaipur", Ergonomics Australia, Vol. 24, No. 1, pp. 1-14, 2010.

[7] P. Mukhopadhyay, "Risk factors in manual brick manufacturing in India", Ergonomics Australia, Vol. 22, No. 1, pp. 16-25, 2008.

[8] E. Nurmianto, "Ergonomic intervention in handicraft producing operation", Proceeding of 9th Asia Pacific Industrial Engineering and Management System, Bali, Indonesia, 3-5 December 2008.

[9] S. Purnawati, "Occupational health and safety-ergonomics improvement as a corporate responsibility of a Bali handicraft company: a case study", Journal of Human Ergology, Vol. 36, No. 2, pp. 75-80, 2007.

[10] M. L. Meena, G. S. Dangayach and A. Bhardwaj "Impact of Ergonomic Factors in Handicraft Industries", Proceeding of International Conference on Mechanical, Production and Automobile Engineering (ICMPAE'2011), Pattaya, Thailand, 17th -18th December, 2011, pp. 247-249.

[11] M. L. Meena, G.S. Dangayach and A. Bhardwaj, "Measuring anthropometric data for designing hand tools in handicraft industries", International Journal of Process Management and Benchmarking, Vol.3, No.3, pp.334 - 351, 2013.

[12] M. L. Meena, G.S. Dangayach and A. Bhardwaj, "Measuring Quality of Work Life Among Workers in Handicraft Industries of Jaipur", International Journal of Industrial and Systems Engineering, Vol.17, No.3, pp.376 - 390, 2014.

[13] M. L. Meena, G. S. Dangayach and A. Bhardwaj, "Investigating Ergonomic Issues among workers in Hand Block Textile Printing Industries", International Journal Business and Systems Research, Vol.8, No.4, pp.392 - 401, 2014.

[14] O. S. Prajapati, A. K. Verma, and M. L. Meena, "Ergonomic redesign and evaluation of children bicycle to protect child abdomen”, Lap Lambert Academic Publishing, Germany, First edition, 2012.

[15] M. L. Meena, and G. S. Dangayach, "An ergonomic approach to design hand tool for screen textile printing", International Journal of Recent advances in Mechanical Engineering, Vol.4, No.2, pp. 5967, 2015.

[16] I. Kuorinka, B. Jonsson, A. Kilbom, H. Vinterberg, F. Biering, G. Andersson, and K. Jorgenesen, "Standard Nordic questionnaires for the analysis of musculoskeletal symptoms", Ergonomics, Vol. 24, No. 2, pp. 91-99, 1987.

[17] E.N. Corlett, and R.P. Bishop, “A technique for assessing postural discomfort”, Ergonomics, Vol. 19, No. 2, pp. 175-182, 1976.

[18] L. McAtamney, and E.N. Corlett, "RULA: a survey method for the investigation of work-related upper limb disorders", Applied Ergonomics, Vol. 24, No. 2, pp. 91-99, 1993.

[19] M.A. Sinclair, "Questionnaire design”, Applied Ergonomics, Vol. 6, No. 2, pp. 73-80, 1975. 
[20] W.G. Lewis, and C.V.Narayan, "Design and sizing of ergonomic handles for hand tools", Applied Ergonomics, Vol. 24, No. 5, pp. 351-356, 1993.

[21] E. Tichauer, "Biomechanics sustains occupational safety and health", Industrial Engineering, Vol. 8, No. 2, pp. 46-56, 1976.

[22] M. Motamedzade, A. Choobineh, M. A. Mououdi, and S. Arghami, "Ergonomic design of carpet weaving hand tools", International Journal of Industrial Ergonomics, Vol. 37, No. 7, pp. 581-587, 2007.

[23] Y. Kong, and B. D. Lowe, "Optimal cylindrical handle diameter for grip force tasks", International Journal of Industrial Ergonomics, Vol. 35, No. 1, pp. 495-507, 2005.

\section{Authors}

M. L. Meena is Assistant Professor in Department of Mechanical Engineering in Malaviya National Institute of Technology (MNIT) Jaipur. He was graduated in Mechanical Engineering from University of Rajasthan, Jaipur in the year 2005. He obtained Master's degree in Manufacturing System Engineering from MNIT Jaipur. He did his Ph.D. from MNIT Jaipur. His research areas are ergonomics and productivity engineering. He has published 10 research papers in various International Journals. He has 08 years of Teaching and Industrial experience.

G. S. Dangayach is Professor in Department of Mechanical Engineering in Malaviya National Institute of Technology (MNIT) Jaipur. He was graduated in Mechanical Engineering from M.B.M. Engineering College Jodhpur in the year 1985. He obtained Master's degree in Production Engineering from Indian Institute of Technology (IIT), Delhi. He earned his Doctorate in Industrial Engineering also at IIT, Delhi. He has published 130 research papers in various National and International Journals. He is Guest Editor of three International Journals viz. Production planning \& Control (PPC), International Journal of Manufacturing Technology \& Management (IJMTM), International Journal of Business Performance Management (IJBPM). He is Reviewer of Eighteen International Journals. He is Visiting Professor at School of Management, Asian Institute of Technology (AIT) Bangkok, IIM Khozikode, IIM Shillong, \& Leeds-Met India, Bhopal. He delivered several Invited Lectures/Key note addresses in India \& abroad. He has 29 years of Teaching and Industrial experience.

A. Bhardwaj is Professor in Department of Mechanical Engineering in Malaviya National Institute of Technology (MNIT) Jaipur. He was graduated in Mechanical Engineering from M.B.M. Engineering College Jodhpur in the year 1985. He earned his Doctorate in Industrial Engineering also at MNIT Jaipur. $\mathrm{He}$ has published various research papers in various National and International Journals. He delivered several Invited Lectures/Key note addresses in India \& abroad. He has 29 years of Teaching and Industrial experience. 